\title{
Clinicopathological Factors that Predict Endocervical Margin Involvement of CIN2+ after Cervical Conization Procedure in the Tertiary Center, Rajavithi Hospital, Thailand
}

\author{
Kamaitorn Tientong $^{1,2}$, Marut Yanaranop ${ }^{1,2}$, Nattharwan Wannatrakool ${ }^{1}$
}

${ }^{1}$ Department of Obstetrics and Gynecology, Rajavithi Hospital, Bangkok, Thailand. ${ }^{2}$ College of Medicine, Rangsit University, Bangkok, Thailand.

\begin{abstract}
Objective: To identify clinicopathological factors that predict endocervical margin involvement of CIN2+ after cervical conization. Methods: 464 patients undergoing LEEP at Department of Obstetrics and Gynecology, Rajavithi Hospital, Thailand between January 2014 and June 2019 were analysed retrospectively. The patients were divided into two groups as a negative and positive endocervical margin of CIN2+. Clinical factors and the cyto-pathological characteristic were included. Univariate and multivariate analysis were used to identify the risk factors predicted positive endocervical margin. Results: $150(32.3 \%, 150 / 464)$ women had endocervical margin involvement of CIN2+. Mean age in positive endocervical margin group was significant older than negative endocervical margin group $(47.8 \pm 12.9$ versus $40.8 \pm 11.5$ years old, $\mathrm{p}<0.001)$. There are more significant post-menopausal women in positive endocervical margin group $(\mathrm{p}<0.001)$. In positive endocervical margin group, there were significant higher grade on cervical cytology, higher grade on histology of LEEP specimen, and glandular involvement of LEEP specimen. In univariate analysis, age of $\geq 50$ years old, post-menopausal status, $\geq$ HSIL on cervical cytology, and glandular involvement of LEEP specimens were independent risk factors for predicting endocervical margin involvement. Moreover, in multivariate analysis, age of $\geq 50$ years old and glandular involvement of LEEP specimen show significant difference between two groups. In endocervical margin involvement of CIN2+ group has $2.84(95 \%$ CI: 1.23-6.56, p $=0.015)$ and $2.41(95 \%$ CI: $1.58-3.66, p<0.001)$ times more age $\geq 50$ years old and glandular involvement of LEEP specimen respectively. Conclusions: The age of $\geq 50$ years old is the only pre-operative variable in this study. This finding is consistent with many previous studies. Therefore, performing LEEP in the women with the age of $\geq 50$ years old should be aware the result of positive endocervical margin.
\end{abstract}

Keywords: Positive endocervical margin- endocervical margin involvement- incomplete excision of cervix

Asian Pac J Cancer Care, 6 (3), 231-236

\section{Introduction}

Cervical intraepithelial neoplasia (CIN) is known as the precancerous lesion of cervical carcinoma. The tendency of developing cervical carcinoma depends on the severity of CIN. CIN1 can spontaneously resolve within one year due to human immune system and this is contrast to CIN2+ which approximately a third of women is more likely to develop cervical carcinoma [1]. Consequently, management guidelines suggest that CIN2+ should be treated.
Submission Date: 08/25/2020Ａcceptance Date: 01/19/2021

\footnotetext{
Corresponding Author:

Dr. Kamaitorn Tientong

Department of Obstetrics and Gynecology, Rajavithi Hospital, Bangkok, Thailand.

Email: tulkamaitorn@gmail.com
}

The standard treatment modality for CIN2+ is conization which is divided into loop electrosurgical excision procedure (LEEP), cold-knife conization, and laser conization. The pathologic examination of conization specimen can confirm the diagnosis that may indicate an occult malignancy, and allow us to obtain the information of the margin of specimen [2]. However, conization reduces the volume and the length of the cervix leading to unfavorable subsequent pregnancy [3]. 
The systematic review and meta-analysis reveal that the risk of residual or recurrent CIN2+ is significantly higher with involved margins on excisional treatment [4]. Although the ectocervical margin is easily evaluated by performing conization under colposcopy or naked eyes after application of Lugol's solution or acetic acid, to determine whether the endocervical margin has been optimally treated is quite difficult [5]. Identification of the risk factors that influence the margin status could tailor management in each woman, avoiding inappropriate and incomplete treatment.

This study aims to identify clinicopathological factors that predict endocervical margin involvement of CIN2+ after cervical conization.

\section{Materials and Methods}

This retrospective observational study involved 464 patients undergoing LEEP at Department of Obstetrics and Gynecology, Rajavithi hospital, Thailand between January 2014 and June 2019. All subjects in our hospital performed the LEEP with conization procedure. For inclusion criteria, all women had to undergo LEEP due to CIN2+ on cervical biopsy, high grade lesion on colposcopy, discrepancy between cytology and histology, cervical biopsy-suspected microinvasive cervical carcinoma and persistent CIN1. 150 of the patients with endocervical margin involvement of CIN2+ were identified. Pregnant women and incomplete data were excluded. This study was approved by the institutional review board of Rajavithi hospital.

Patient characteristics were extracted form medical record including age, parity, HIV infection, and menopausal status. The cyto-pathological characteristic of Pap test, adequacy of colposcopy, histology of colposcopic-direct biopsy, top hat procedure, fragmentation of specimen, length of cervical specimen, and histology and glandular involvement of LEEP specimens were also retrieved.

The LEEP was conducted by gynecologic oncologist, resident and fellow under the supervision of a staff member in Gynecologic Oncology Unit. The cervical specimen was sent to the Department of Pathology and all specimens were reviewed by experienced pathologists. The margin status of CIN2+ was recorded from the final pathological report and divided into two groups as endocervical and ectocervical margin involvement. Post-excisional followup included Pap test with or without endocervical curettage (ECC) and repeated excisional biopsy or hysterectomy if clinical result was indicated.

All statistical calculations were done using SPSS statistics software package, version 20.0. Continuous variables were shown as mean and standard deviation and compared by a Student's t-test. Categorical variables were expressed as a number and a percentage, compared by a Fisher's exact and Pearson's chi- squared test. All variables in univariable analysis that had p-value less than 0.05 were carried out to identify the independent risk factors in multivariate logistic regression. The $\mathrm{p}$-value that was less than 0.05 was considered as statistical significance.

\section{Results}

According to 464 women who underwent LEEP due to CIN2+ on cervical biopsy, high grade lesion on colposcopy, discrepancy between cytology and histology, cervical biopsy-suspected microinvasive cervical carcinoma, and persistent CIN1, 314 (67.7\%, 314/464) of the women had no endocervical margin involvement of CIN2+ and $150(32.3 \%, 150 / 464)$ of the women had endocervical margin involvement of CIN2+. Table 1 shows clinico-cytopathological characteristics of the patients comparing between negative and positive endocervical margin of $\mathrm{CIN} 2+$. Mean age in positive endocervical margin group was significantly older than negative endocervical margin group $(47.8 \pm 12.9$ versus $40.8 \pm 11.5$ years old, $\mathrm{p}<0.001)$. Significantly more post-menopausal women were found in positive endocervical margin group $(\mathrm{p}<0.001)$. In positive endocervical margin group, there were significantly higher grade on cervical cytology, higher grade on histology of LEEP specimen, and glandular involvement of LEEP specimen.

Table 2 reveals univariate and multivariate analysis of clinicopathological factors predicted the risk of endocervical margin involvement of CIN2+. In univariate analysis, age of $\geq 50$ years old, post-menopausal status, $\geq$ HSIL on cervical cytology, and glandular involvement of LEEP specimens were independent risk factors for predicting endocervical margin involvement. Moreover, in multivariate analysis, age of $\geq 50$ years old and glandular involvement of LEEP specimen show significant difference between two groups. In endocervical margin involvement of CIN2+ group, the table showed 2.84 times (95\% CI: $1.23-6.56, \mathrm{p}=0.015)$ among age $\geq 50$ years old and 2.41 times (95\% CI: $1.58-3.66, \mathrm{p}<0.001$ ) on glandular involvement of LEEP specimen compared with no margin involvement respectively.

The Table 3 identified the data during follow-up period. Re-LEEP were performed in $17(5.4 \%, 17 / 314)$ women with negative endocervical margin of CIN2+ group and $62(41.3 \%, 62 / 150)$ women with positive endocervical margin of CIN2+ group. The rate of residual/recurrent CIN2+ was $27.3 \%(41 / 150)$ in women who underwent Re-LEEP for positive endocervical margins associated with CIN2+, while the rate of recurrent CIN2+ was $3 \%(12 / 314)$ in women who underwent Re-LEEP for negative endocervical margins associated with CIN2+. Similarly, $19(6 \%, 19 / 314)$ and $31(20.7 \%, 31 / 150)$ women performed hysterectomies with negative and positive endocervical margin of CIN2+ group, respectively. When two groups were compared, residual/recurrent CIN2+ was significantly found in positive endocervical margin groups after performing Re-LEEP and hysterectomy $(p<0.001)$. Finally, there was significant difference in cervical cytology at 12 months of follow up $(p=0.006)$.

\section{Discussion}

Meta-analysis and systematic review demonstrate that incomplete removal of precancerous lesion of cervix has increased the risk of residual or recurrent disease 
Table 1. Clinico-cytopathological Characteristics of the Patients with Negative and Positive Endocervical Margin of CIN2+

\begin{tabular}{|c|c|c|c|c|}
\hline Characteristics & $\begin{array}{c}\text { Total } \\
\mathrm{N}=464\end{array}$ & $\begin{array}{l}\text { Negative Endocervical Margin of CIN2+ } \\
\qquad \mathrm{N}=314\end{array}$ & $\begin{array}{l}\text { Positive EndocervicalMargin of CIN2+ } \\
\qquad N=150\end{array}$ & p-value \\
\hline Age $($ Mean \pm SD) & $43.1 \pm 12.4$ & $40.8 \pm 11.5$ & $47.8 \pm 12.9$ & $<0.001$ a* \\
\hline \multicolumn{5}{|l|}{ Parity } \\
\hline 0 & $92(19.8 \%)$ & $67(21.3 \%)$ & $25(16.7 \%)$ & \multirow[t]{2}{*}{$0.238^{b}$} \\
\hline$\geq 1$ & $372(80.2 \%)$ & $247(78.7 \%)$ & $125(83.3 \%)$ & \\
\hline \multicolumn{5}{|l|}{ HIV infection } \\
\hline Positive & $49(10.6 \%)$ & $39(12.4 \%)$ & $10(6.7 \%)$ & \multirow[t]{2}{*}{$0.059^{b}$} \\
\hline Negative & $4115(89.4 \%)$ & $275(87.6 \%)$ & $140(93.3 \%)$ & \\
\hline \multicolumn{5}{|l|}{ Menopausal Status } \\
\hline Pre-menopause & $337(72.6 \%)$ & $248(79 \%)$ & $89(59.3 \%)$ & \multirow[t]{2}{*}{$<0.001$ b* } \\
\hline Post-menopause & $127(27.4 \%)$ & $66(21 \%)$ & $61(40.7 \%)$ & \\
\hline \multicolumn{5}{|l|}{ Cervical cytology } \\
\hline ASC-US & $34(7.3 \%)$ & $26(8.3 \%)$ & $8(5.3 \%)$ & \multirow[t]{5}{*}{$0.026^{\mathrm{b} *}$} \\
\hline CIN1 & $43(9.3 \%)$ & $35(11.2 \%)$ & $8(5.3 \%)$ & \\
\hline CIN 2-3/ASC-H & $342(73.7 \%)$ & $227(72.3 \%)$ & $115(76.7 \%)$ & \\
\hline $\mathrm{AGC}$ & $11(2.4 \%)$ & $9(2.9 \%)$ & $2(1.3 \%)$ & \\
\hline SCC/AdenoCA & $34(7.3 \%)$ & $17(5.4 \%)$ & $17(11.3 \%)$ & \\
\hline \multicolumn{5}{|l|}{ Colposcopy } \\
\hline Adequate $\mathrm{T}$ zone & $385(83.0 \%)$ & $264(84.1 \%)$ & $121(80.7 \%)$ & \multirow[t]{2}{*}{$0.361^{\mathrm{b}}$} \\
\hline Inadequate $\mathrm{T}$ zone & $79(17.0 \%)$ & $50(15.9 \%)$ & $29(19.3 \%)$ & \\
\hline \multicolumn{5}{|c|}{ Histology of Colposcopic-direct biopsy } \\
\hline Not done & $175(37.7 \%)$ & $120(38.2 \%)$ & $55(36.7 \%)$ & \multirow[t]{5}{*}{$0.167^{\mathrm{c}}$} \\
\hline Negative & $34(7.3 \%)$ & $24(8.6 \%)$ & $7(4.7 \%)$ & \\
\hline CIN1 & $9(1.9 \%)$ & $8(2.6 \%)$ & $1(0.7 \%)$ & \\
\hline CIN2/3/CIS & $243(52.4 \%)$ & $158(50.3 \%)$ & $85(56.7 \%)$ & \\
\hline SCC/adenoCA & $3(0.7 \%)$ & $1(0.3 \%)$ & $2(1.3 \%)$ & \\
\hline \multicolumn{5}{|c|}{ Glandular involvement (LEEP) } \\
\hline Yes & $225(48.5 \%)$ & $129(41.1 \%)$ & $96(64.0 \%)$ & \multirow[t]{2}{*}{$<0.001$ b* } \\
\hline No & $239(51.5 \%)$ & $185(58.9 \%)$ & $54(36.0 \%)$ & \\
\hline \multicolumn{5}{|l|}{ Top hat procedure } \\
\hline Done & $134(28.9 \%)$ & $94(30 \%)$ & $40(26.7 \%)$ & \multirow[t]{2}{*}{$0.467^{\mathrm{b}}$} \\
\hline Not done & $330(71.1 \%)$ & $220(70.1 \%)$ & $110(73.3 \%)$ & \\
\hline \multicolumn{5}{|c|}{ Fragmentations of specimen } \\
\hline 1 & $322(69.4 \%)$ & $227(70.7 \%)$ & $100(66.7 \%)$ & \multirow[t]{3}{*}{$0.150^{b}$} \\
\hline 2 & $132(28.5 \%)$ & $88(28.0 \%)$ & $44(29.3 \%)$ & \\
\hline$\geq 3$ & $10(2.2 \%)$ & $4(1.3 \%)$ & $6(4 \%)$ & \\
\hline Length ((Median \pm SD) & $1.0(0.3-3.0)$ & $1(0.4-3.0)$ & $1(0.3-3.0)$ & $0.66^{\mathrm{d}}$ \\
\hline \multicolumn{5}{|l|}{ Length of specimen } \\
\hline$<7 \mathrm{~mm}$ & $67(14.4 \%)$ & $42(13.4 \%)$ & $25(16.7 \%)$ & \multirow[t]{2}{*}{$0.346^{b}$} \\
\hline$\geq 7 \mathrm{~mm}$ & $397(85.6 \%)$ & $272(86.6 \%)$ & $125(83.3 \%)$ & \\
\hline \multicolumn{5}{|l|}{ Histology of LEEP } \\
\hline Negative & $11(2.4 \%)$ & $11(3.5 \%)$ & $0(0 \%)$ & \multirow[t]{4}{*}{$0.001^{\mathrm{c}^{*}}$} \\
\hline CIN1 & $12(2.6 \%)$ & $12(3.8 \%)$ & $0(0 \%)$ & \\
\hline CIN2/3/CIS & $429(92.5 \%)$ & $285(90.8 \%)$ & $144(96.0 \%)$ & \\
\hline SCC/AdenoCA & $12(2.6 \%)$ & $6(1.9 \%)$ & $6(4 \%)$ & \\
\hline
\end{tabular}


Table 2. Univariate and Multivariate Analysis of Clinicopathological Factors Predicted the Risk

\begin{tabular}{|c|c|c|c|c|}
\hline \multirow[t]{2}{*}{ Variables } & \multirow{2}{*}{$\begin{array}{c}\text { Univariate analysis } \\
\text { OR }(95 \% \mathrm{CI})\end{array}$} & \multicolumn{3}{|c|}{ Multivariate analysis } \\
\hline & & p-value & OR $(95 \% \mathrm{CI})$ & $\mathrm{p}$-value \\
\hline \multicolumn{5}{|l|}{ Age } \\
\hline$<50$ years & 1 & & 1 & \\
\hline$\geq 50$ years & $2.82(1.85-4.29)$ & $<0.001 *$ & $2.84(1.23-6.56)$ & $0.015^{*}$ \\
\hline \multicolumn{5}{|l|}{ Parity } \\
\hline 0 & 1 & & - & - \\
\hline$\geq 1$ & $1.36(0.82-2.25)$ & 0.239 & - & - \\
\hline \multicolumn{5}{|c|}{ Menopause status (no/yes) } \\
\hline Pre-menopause & 1 & & 1 & \\
\hline Post-menopause & $2.58(1.69-3.94)$ & $<0.001 *$ & $0.98(0.42-2.30)$ & 0.968 \\
\hline \multicolumn{5}{|l|}{ Cervical cytology } \\
\hline$<$ HSIL & 1 & & 1 & \\
\hline$\geq \mathrm{HSIL}$ & $2.02(1.12-3.64)$ & $0.019 *$ & $1.53(0.82-2.83)$ & 0.18 \\
\hline \multicolumn{5}{|l|}{ Colposcopy } \\
\hline Adequate $\mathrm{T}$ zone & 1 & & - & - \\
\hline Inadequate $\mathrm{T}$ zone & $1.27(0.76-2.10)$ & 0.361 & - & - \\
\hline \multicolumn{5}{|l|}{ Glandular involvement } \\
\hline No & 1 & & 1 & \\
\hline Yes & $2.55(1.71-3.81)$ & $<0.001 *$ & $2.41(1.58-3.66)$ & $<0.001^{*}$ \\
\hline \multicolumn{5}{|l|}{ Top hat procedure } \\
\hline Done & 1 & & - & - \\
\hline Not done & $1.18(0.76-1.82)$ & 0.468 & - & - \\
\hline \multicolumn{5}{|c|}{ Fragmentation of specimen } \\
\hline 1 & 1 & & - & - \\
\hline$>1$ & $1.21(0.79-1.83)$ & 0.378 & - & - \\
\hline \multicolumn{5}{|l|}{ Length (mm) } \\
\hline$<7$ & 1 & & - & - \\
\hline$\geq 7$ & $0.77(0.45-1.32)$ & 0.346 & - & - \\
\hline
\end{tabular}

* Statistically significant; Abbreviation, HSIL, High grade Squamous Intraepithelial Lesion; T zone, Transformation zone

by about five times compared with that in women with precancerous-free resection margin [4]. Cervical excisional margin involvement reflects treatment failure and should be considered as a quality of clinical practice. However, conization has an effect on subsequent pregnancy outcomes such as preterm delivery and cervical incompetency. Therefore, treatment of precancerous lesion should balance between the adequate conization and iatrogenic harm. The evaluation of ectocervical margin involvement is easily performed with conization under colposcopy or conization after application of Lugol's solution or acetic acid but it is difficult if assessed by means of endocervical involvement.

Many studies have evaluated the effect of cone margin involvement and the risk of residual or recurrent CIN2+ [4-7] but a few studies have been published about the risk factors for predicting positive or negative cone margins. In the previous studies, it shows the discordance of an association between age, parity, smoking, cytologic grade, fragmentation of specimen, lesion extension, and cone margin status [8-10]. The lesions of elderly women approaching menopause retract deeper into the cervical canal than in younger women [5]. Many studies have demonstrated increasing age as a risk factor for cone margin involvement $[5,11,12]$. One study showed that cone length was the best predictor of cone margin status and the addition of age factor or preceding cervical cytology to cone dimensions did not significantly improve the prediction of incomplete cervical excision [13]. From our multivariate analysis, the risk of positive endocervical margin of CIN2+ increases in women age of $\geq 50$ years old (2.84 times compared with age $<50$ years old) and positive glandular involvement of LEEP specimen (2.41 times compared with negative glandular involvement). It is established that the chance of complete cervical excision increased with increasing cone length [14]. For this reason, LEEP in the patient with age of $\geq 50$ years old should be deeply cut. It is expected that top hat procedure will be protective factor for endocervical margin involvement, but no significant difference is shown in univariate analysis. The result of this study differs from the previous studies which did not demonstrate relationship between parity, menopausal status, preceding cervical cytology, adequacy of colposcopy, top hat 
Table 3. The Re-LEEP, Hysterectomy, and Cervical Cytology at 12 Months Comparing between Negative and Positive Endocervical Margin of CIN2+

\begin{tabular}{|c|c|c|c|c|}
\hline Follow up & $\begin{array}{c}\text { Total } \\
\mathrm{N}=464\end{array}$ & $\begin{array}{l}\text { Negative Endocervical Margin of CIN2+ } \\
\qquad N=314\end{array}$ & $\begin{array}{l}\text { Positive EndocervicalMargin of CIN2+ } \\
\qquad \mathrm{N}=150\end{array}$ & $\mathrm{p}$-value \\
\hline \multicolumn{5}{|l|}{ Re-LEEP } \\
\hline Not done & $385(83.0 \%)$ & $297(94.6 \%)$ & $88(58.7 \%)$ & $<0.001 \mathrm{c}^{\mathrm{c}^{*}}$ \\
\hline Negative & $21(4.5 \%)$ & $3(1.0 \%)$ & $18(12.0 \%)$ & \\
\hline CIN1 & $5(1.1 \%)$ & $2(0.6 \%)$ & $3(2.0 \%)$ & \\
\hline CIN2/3/CIS & $47(10.1 \%)$ & $12(3.8 \%)$ & $35(23.3 \%)$ & \\
\hline SCC/AdenoCA & $6(1.3 \%)$ & $0(0 \%)$ & $6(4.0 \%)$ & \\
\hline \multicolumn{5}{|l|}{ Hysterectomy } \\
\hline Not done & $414(89.2 \%)$ & $295(94 \%)$ & $119(79.3 \%)$ & $<0.0011^{\mathrm{c}^{*}}$ \\
\hline Negative & $17(3.7 \%)$ & $10(3.2 \%)$ & $7(4.7 \%)$ & \\
\hline CIN1 & $1(0.2 \%)$ & $0(0 \%)$ & $1(0.7 \%)$ & \\
\hline CIN2/3/CIS & $19(4.1 \%)$ & $3(1.0 \%)$ & $16(10.7 \%)$ & \\
\hline SCC/AdenoCA & $13(2.8 \%)$ & $6(1.9 \%)$ & $7(4.7 \%)$ & \\
\hline \multicolumn{5}{|l|}{ Cervical and vaginal cytology } \\
\hline \multicolumn{5}{|l|}{ (Follow-up at 12 months) } \\
\hline Normal & $426(92.0 \%)$ & $299(95.2 \%)$ & $127(85.2 \%)$ & $0.006^{\mathrm{c}^{*}}$ \\
\hline ASC-US & $6(1.3 \%)$ & $2(0.6 \%)$ & $4(2.7 \%)$ & \\
\hline LSIL & $3(0.7 \%)$ & $1(0.2 \%)$ & $2(1.3 \%)$ & \\
\hline ASC-H/HSIL/AGC/VAIN3 & $18(3.9 \%)$ & $7(2.2 \%)$ & $11(7.3 \%)$ & \\
\hline SCC/AdenoCA & $3(0.7 \%)$ & $1(0.3 \%)$ & $2(1.3 \%)$ & \\
\hline Loss follow up & $7(1.5 \%)$ & $4(1.3 \%)$ & $3(2.0 \%)$ & \\
\hline
\end{tabular}

a Student's t-test, ${ }^{\mathrm{b}}$ Pearson's chi- squared test, and ${ }^{\mathrm{c}}$ Fisher's exact test were used. ${ }^{*}$ Statistically significant. Abbreviation, ASC-US, Atypical Squamous Cells of Undetermined Significance; CIN, Cervical Intraepithelial Neoplasia; ASC-H, atypical squamous cells- cannot exclude HSIL; AGC, Atypical Glandular cells; SCC, Squamous Cell Carcinoma; AdenoCA, Adenocarcinoma; HSIL, High grade Squamous Intraepithelial Lesion; LEEP, Loop Electrosurgical Excisional Procedure; VAIN, Vaginal Intraepithelial Neoplasia

procedure, fragmentation of specimen, length of specimen, and endocervical margin involvement of CIN2+.

The percentage of negative endocervical margin status in this study was $67.7 \%(314 / 464)$. In this study, the follow up of the recurrence/persistence in case of negative and positive cervical excision is carried out which reflects clinical significance of the positive cervical margin involvement of CIN2+, since not all of the women with positive margins have residual disease and most cases of residual disease naturally regress [8]. In our practice, when positive endocervical margin is detected, certain choices of treatment will be repeated which include Pap test with or without ECC or repeated excisional biopsy depending on doctor preference and age of patients. Hysterectomy is not performed in all women with endocervical margin involvement. When the Pap test shows abnormal finding, patients will be reevaluated. The re-evaluation involves using colposcopy with colposcopic-directed biopsy, and re-excision of cervix. Hysterectomy is performed only when repeat conization is technically impossible in CIN2+ patients with positive margins. Hence, rate of hysterectomy in our center is quite low $(10.8 \%, 50 / 464)$. Furthermore, after period of 12 months follow up, there was significant difference of cervical cytology between negative and positive endocervical margin.

The strength of the study is the large number of participants: the patients which represent an adequate sample of the general population. In addition, all histology of LEEP specimen is under the review of experienced pathologist. However, retrospective nature seems to be the limitation of the present study and certain important pre-operative variables, such as lesion extension, are excluded. For the future study, application of HPV infection should be combined so as to predict margin status.

In conclusion, the presence of pre-operative risk factors can assist in guiding the treatment plan. The age of $\geq 50$ years old is the only pre-operative variable in this study. This finding is consistent with many previous studies. Therefore, performing LEEP among the women with the age of $\geq 50$ years old should be aware of the result of positive endocervical margin. Furthermore, if preceding cervical biopsy revealed glandular involvement, LEEP should be also performed carefully. Long-term follow-up is essential for women treatment, no matter what the excision status is.

\section{Acknowledgments}

This research investigation was made in part by grants from the Research Fund of Rajavithi Hospital. The authors wish to thank gynecologic staff, fellows and residents at the Department of Obstetrics and Gynecology, Rajavithi Hospital. 


\section{References}

1. McCredie MR, Sharples KJ, Paul C, Baranyai J, Medley G, Jones RW, Skegg DC. Natural history of cervical neoplasia and risk of invasive cancer in women with cervical intraepithelial neoplasia 3: a retrospective cohort study. The Lancet Oncology. 2008 05;9(5):425-434. https://doi. org/10.1016/s1470-2045(08)70103-7

2. Martin-Hirsch P, Paraskevaidis E, Bryant A, Dickinson H, Keep S. Surgery for cervical intraepithelial neoplasia. Cochrane Database Syst Rev. 2010;16:CD001318. https:// doi.org/10.1002/14651858.CD001318.pub2

3. Kyrgiou M, Koliopoulos G, Martin-Hirsch P, Arbyn M, Prendiville W, Paraskevaidis E. Obstetric outcomes after conservative treatment for intraepithelial or early invasive cervical lesions: systematic review and meta-analysis. The Lancet. 2006 02;367(9509):489-498. https://doi. org/10.1016/s0140-6736(06)68181-6

4. Arbyn M, Redman CWE, Verdoodt F, Kyrgiou M, Tzafetas M, Ghaem-Maghami S, Petry K, Leeson S, Bergeron C, Nieminen P, Gondry J, Reich O, Moss EL. Incomplete excision of cervical precancer as a predictor of treatment failure: a systematic review and meta-analysis. The Lancet Oncology. 2017 Dec;18(12):1665-1679. https://doi. org/10.1016/s1470-2045(17)30700-3

5. Bae HS, Chung YW, Kim T, Lee KW, Song JY. The appropriate cone depth to avoid endocervical margin involvement is dependent on age and disease severity. Acta Obstetricia et Gynecologica Scandinavica. 2012 Dec 05;92(2):185-192. https://doi.org/10.1111/aogs. 12025

6. Petry KU, Nieminen PJ, Leeson SC, Bergeron CO, Redman CW. 2017 update of the European Federation for Colposcopy (EFC) performance standards for the practice of colposcopy. European Journal of Obstetrics \& Gynecology and Reproductive Biology. 2018 05;224:137-141. https://doi. org/10.1016/j.ejogrb.2018.03.024

7. Alder S, Megyessi D, Sundström K, Östensson E, Mints M, Belkić K, Arbyn M, Andersson S. Incomplete excision of cervical intraepithelial neoplasia as a predictor of the risk of recurrent disease - a 16-year follow-up study. American Journal of Obstetrics and Gynecology. 2020 02;222(2): 172. e1-172.e12. https://doi.org/10.1016/j.ajog.2019.08.042

8. Chen Y, Lu H, Wan X, Lv W, Xie X. Factors associated with positive margins in patients with cervical intraepithelial neoplasia grade 3 and postconization management. International Journal of Gynecology \& Obstetrics. 200907 22;107(2):107-110. https://doi.org/10.1016/j. ijgo.2009.05.027

9. Sun X, Ma S, Zhang J, Wu M. Predictors and clinical significance of the positive cone margin in cervical intraepithelial neoplasia III patients. Chin Med J. 2009;122:367-72.

10. Yingyongwatthanawitthaya T, Chirdchim W, Thamrongwuttikul C, Sananpanichkul P. Risk Factors for Incomplete Excision after Loop Electrosurgical Excision Procedure (LEEP) in Abnormal Cervical Cytology. Asian Pacific Journal of Cancer Prevention. 2017 09;18(9). https:// doi.org/10.22034/APJCP.2017.18.9.2569

11. Costa S, De Nuzzo M, Terzano P, et al. Factors associated with cone margin involvement in CIN patients undergoing conization-equivalent electrosurgical procedure. Acta Obstet Gynecol Scand. 2000;79:586-92.

12. Bentley J, Bentley J, Bertrand M, Brydon L, Gagné H, Hauck B, Mayrand M, McFaul S, Power P, Schepansky A, Straszak-Suri M, Colgan T, Geldenhuys L, Heywood M, Howlett R, Kapusta L, Kupets R, Murphy J, Nation J, Senikas V, Shier M. Colposcopic Management of Abnormal
Cervical Cytology and Histology. Journal of Obstetrics and Gynaecology Canada. 2012 Dec;34(12):1188-1202. https:// doi.org/10.1016/s1701-2163(16)35468-8

13. Giannella L, Di Giuseppe J, Prandi S, Delli Carpini G, Tsiroglou D, Ciavattini A. What is the value of pre-surgical variables in addition to cone dimensions in predicting cone margin status?. European Journal of Obstetrics \& Gynecology and Reproductive Biology. 2020 01;244:180184. https://doi.org/10.1016/j.ejogrb.2019.11.017

14. Kawano K, Tsuda N, Nishio S, Yonemoto K, Tasaki K, Tasaki R, Ushijima K. Identification of appropriate cone length to avoid positive cone margin in high grade cervical intraepithelial neoplasia. Journal of Gynecologic Oncology. 2016;27(5). https://doi.org/10.3802/jgo.2016.27.e54

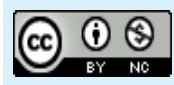

This work is licensed under a Creative Commons AttributionNon Commercial 4.0 International License. 